\title{
The Effects of Nickel and Carbon Concentrations on the Wear Resistance of Fe-Ni-C Austenitic Alloys
}

\author{
Shin Gyeong Su, Ji Hui Kim and Seon Jin Kim ${ }^{\mathrm{a}}$ \\ Division of materials science and engineering, Hanyang university, Seoul, 133-791, Korea
}

\begin{abstract}
The effects of nickel and carbon concentrations on the wear resistance of Fe-xNi-yC ( $\mathrm{x}=14 \sim 20$ wt. \%, $\mathrm{y}=0.6 \sim 1.0$ wt. \%) were investigated with respect to strain energy initiation of the martensitic transformation and hardness. The strain energy needed to initiate the martensitic transformation increased with increasing carbon and nickel concentrations, except in $1.0 \mathrm{wt} . \% \mathrm{C}$ alloys. The wear resistance of the material decreased with increasing carbon concentration up to $0.9 \mathrm{wt}$. \% C. This effect is most likely due to decrement of the martensite volume fraction with increasing carbon concentration induced by the incremental strain energy required to begin the martensitic transformation. In the case of $1.0 \mathrm{wt}$ \% C, the improved wear resistance may be due to carbide precipitation.
\end{abstract}

\section{Introduction}

The wear behavior of commercial 304 and 316 austenitic stainless steels depend upon their austenite stability with respect to the martensitic transformation [1]. Other research shows that strain-induced martensitic transformation can increase wear resistance [2]. Based on these studies, strain-induced martensitic transformation is expected to improve the wear resistance of austenitic steels. Adhesive wear resistance, in particular, would be expected to increase owing to the absorption of applied external energy and increasing hardness during the $\gamma \rightarrow \alpha^{\prime}$ phase transformation [3-5]. However, the sole effect of strain-induced martensitic transformation on the improvement of adhesive wear resistance has not yet been investigated. In this study, the effect of nickel and carbon on strain-induced martensitic transformation of austenitic steels was investigated by measuring the critical energy required to initiate strain-induced martensitic transformation (CESIMT). The relationship between the critical energy and the adhesive wear resistance of the material was also investigated with Fe-xNi-yC ( $x=14 \sim 20$ wt. \%, y=0.6 1.0 wt. \%) alloys.

\section{Experimental procedure}

Fe-xNi-yC ( $\mathrm{x}=14 \sim 20$ wt. \%, $\mathrm{y}=0.6 \sim 1.0$ wt. \%) alloys were prepared by an induction melting furnace in an Ar atmosphere. Nickel and carbon concentration was varied in order to make the carbide-free and fully austenitic phases. Tensile tests were performed at the room temperature at a strain rate of $1.667 \times 10^{-3} \mathrm{~s}^{-1}$ by attaching a feritscope on the tensile specimen. The feritscope was used to detect the amount of martensite phase transformed during tensile tests. The energy needed to form 0.3 vol. \% martensite was defined as the critical energy required to initiate strain-induced martensitic transformation (CESIMT) because martensite was not clearly observed under an optical microscope when the martensite volume fraction was less then 0.3 vol. \%. The CESIMTs were obtained from strain-stress curves. Adhesive wear tests were performed up to 1000 cycles with self-mated specimens at room temperature under a contact stress of $69 \mathrm{MPa}$. The sliding speed and stroke were $4.5 \mathrm{~mm} \mathrm{~s}^{-1}$ and $9 \mathrm{~mm}$, respectively. The weight lost of specimens was measured during the sliding test.

\section{Results and discussion}

The CESIMT as a function of carbon and nickel concentration is presented in Fig. 2. It was recognized from Fig. 1 that the CESIMT increased exponentially when the carbon concentration ranged from $0.6 \mathrm{wt} . \%$ to 0.9 wt. $\%$; after 0.9 wt. \%, CESIMT reached saturation. In addition, as the nickel concentration increased, the CESIMT increased for all concentrations of carbon. It is thought that the stability of austenite increases with

a e-mail: al loylabehanyang.ac.kr

This is an Open Access article distributed under the terms of the Creative Commons Attribution-Noncommercial License (http://creativecommons.org/licenses/by-nc/3.0/), which permits unrestricted use, distribution, and reproduction in any noncommercial medium, provided the original work is properly cited. 
increasing nickel and carbon concentration and it was difficult to achieve the transformation into martensite during the tensile test $[6,7]$.

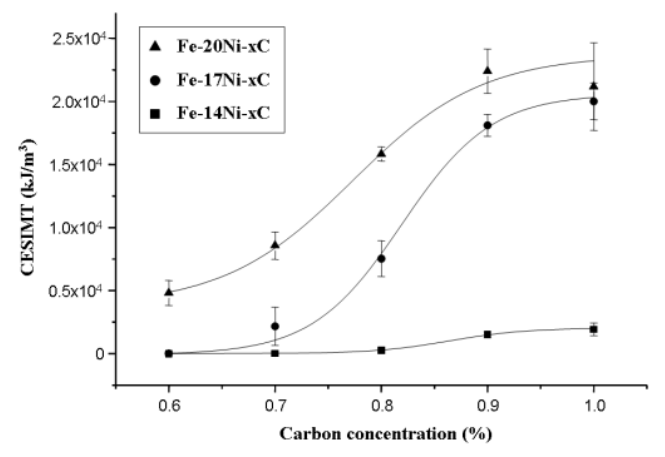

Fig. 1. CESIMT with varying nickel and carbon concentrations

To correlate the CESIMT with their composition, we attempted some simple multidimensional linear least square regression fits of the data for $\mathrm{Fe}-\mathrm{xNi}-\mathrm{yC}$ alloys and the following expression was obtained:

$$
\text { CESIMT }=-6.0+3.6(\text { wt. } \% \mathrm{C})+0.23(\text { wt. } \% \mathrm{Ni})\left(10^{4} \mathrm{~kJ} / \mathrm{m}^{3}\right)
$$

Eq. [1] shows that carbon and nickel increases CESIMT and the increment of CESIMT by carbon is 16 times bigger than that of CESIMT by nickel. The tendency of CESIMT is analogous to that of austenite stability with increasing nickel and carbon. Eq. [1] correlates reasonably well with obtained CESIMT data, as can be seen in Fig. 2.

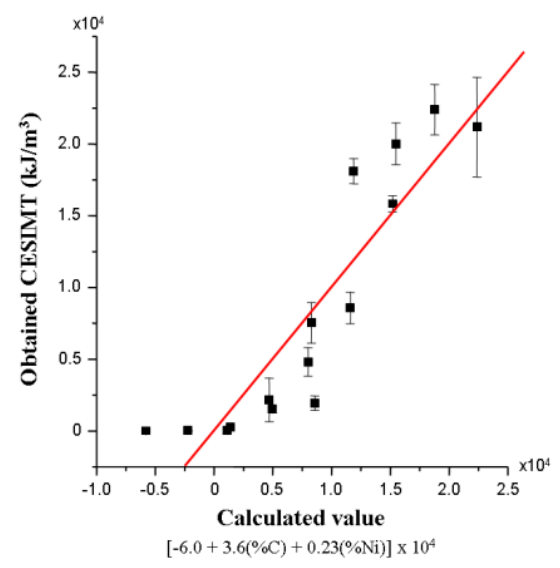

Fig. 2. Linear regression analysis of data for Fe-Ni-C alloys.

The total martensite volume fractions and the total weight losses after 1000 cycles wear tests are presented in Fig. 3 (a) and (b), respectively. In Fig. 3 (a), the martensite volume fraction of the worn surfaces decreased with increasing carbon and nickel concentrations. As the nickel concentration increased from 14 to $20 \mathrm{wt}$. \%, the total weight losses also increased. However, there was an abrupt drop in weight losses at $1.0 \mathrm{wt}$. \% C for all concentrations of nickel. According to Fontalvo's research [8], carbides prevent the metal-to-metal contact between wear surfaces and consequently result in increased adhesive wear resistance. Thus, we hypothesize that the abrupt decrease of weight losses at $1.0 \mathrm{wt} . \% \mathrm{C}$ can be attributed to the presence of carbides. 

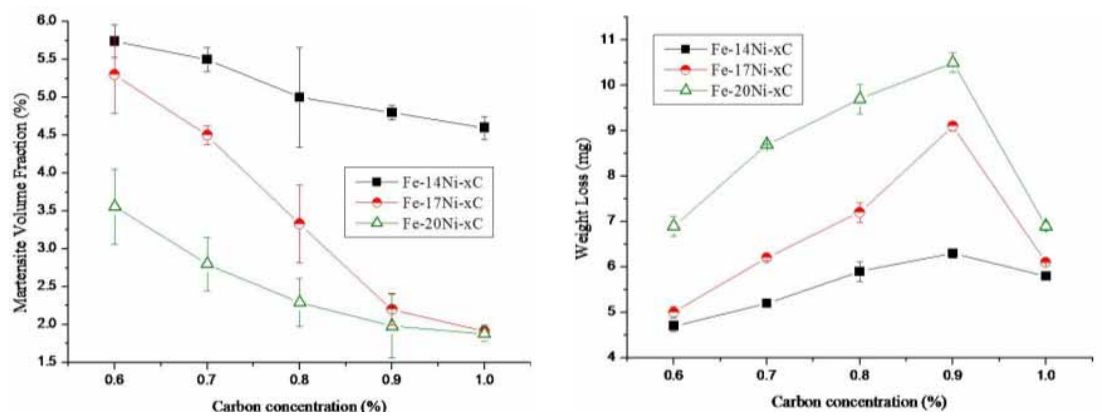

Fig. 3. Martensite volume fraction and weight losses after the wear tests with varying nickel and carbon concentrations

Figure 4 (a) shows the point in the wear testing at which the martensite volume fractions stopped increasing. After a certain number of cycles, the martensite volume fraction was saturated. Fig. 4 (b) summarizes the number of cycles at which saturation occurs for varying carbon and nickel concentrations. The number of cycles before saturation decreased up to $0.9 \mathrm{wt} . \% \mathrm{C}$, and then they increased at $1.0 \mathrm{wt}$. \% C. As the nickel concentration increased from 14 to $20 \mathrm{wt} \%$, the number of cycles before saturation decreased. According to Zhang and Wang's reports [3-4], energy absorption during strain-induced martensitic transformation was thought to be one of the factors that increases wear resistance. According to this theory, a low CESIMT alloy will have a higher fraction of austenite phases was transformed into martensite than will a high CESIMT alloy at the same number of test cycles. The better wear resistance of the low CESIMT alloys was thought to be due to the relatively higher martensite volume fraction and the relatively fewer number of cycles needed to transform into martensite. However, Fig. 4 (b) presents the unexpected sudden increase of the number of cycles needed for saturation at $1.0 \mathrm{wt}$. \% C. One of the factors contributing to this result may be the smaller amount of friction present due to carbides preventing the metal-to-metal contact on the wear surfaces [8]. Hence, it was conceivable that a smaller amount of friction energy of the martensitic transformation by precipitated carbides delayed the saturation cycles in $1.0 \mathrm{wt}$ \% $\mathrm{C}$ alloys.
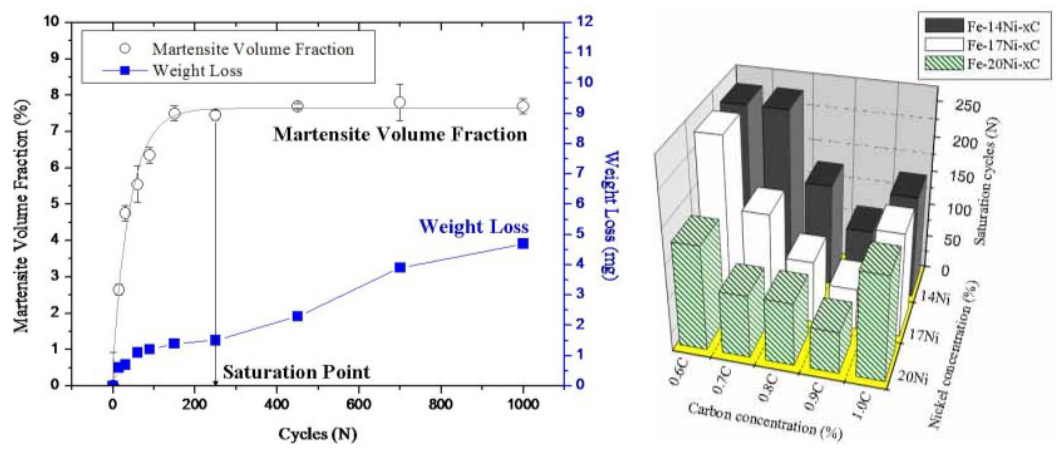

Fig. 4. (a) The weight losses and martensite volume fraction of Fe-14Ni-0.6C as a function of wear test cycles and (b) the number of cycles at saturation with varying nickel and carbon concentrations.

\section{Conclusions}

The following conclusion can be drawn from tensile tests and adhesive wear tests of Fe-Ni-C austenitic alloys with varying nickel and carbon concentrations:

1. As carbon and nickel concentrations increase, the critical strain energy for strain-induced martensitic transformation (CESIMT) decreases.

2. An attempt was made to establish a relationship between CESIMT and composition of alloying elements for Fe-Ni-C alloys. The resulting expression CESIMT $=-6.0+3.6$ (wt. \% C) +0.23 (wt. \% Ni) $\left(\mathrm{x}^{4} 0^{4} \mathrm{~kJ} / \mathrm{m}^{3}\right)$ reasonably correlates with obtained CESIMT data.

3. In 1.0 wt. $\% \mathrm{C}$ alloys, CESIMT was saturated as a result of the maximum carbon solubility of the in austenite phase being reached between 0.9 and 1.0 wt. \% $\mathrm{C}$. 
4. The adhesive wear resistance generally increases as the CESIMT decreases. Strain-induced martensitic transformation seems to improve the adhesive wear resistance of these materials as a result of high surface hardness and absorption of friction energy. In the case of $1.0 \mathrm{wt} \% \mathrm{C}$, the improved wear resistance may be due to carbide precipitation.

\section{References}

[1] K. L. Hsu, T. M. Ahn and D. A. Rigney, Wear, Vol. 60 (1980) pp. 13-37

[2] K. Lee, K. H. Ko, J. H. Kim, G. G. Kim and S. Kim, Tribology Letters, Vol. 26 (2007) pp. 131-135

[3] T. C. Zhang and D. Y. Li, Materials Science and Engineering A, Vol. A329-331 (2002) pp. 563-567

[4] Z. Wang and J. Zhu, Wear, Vol. 256 (2004) pp. 1208-1213

[5] K. Lee, S. Lee, Y. Kim, H. S. Hong, Y. Oh and S. Kim, Wear, Vol. 255 (2003) pp. $481-488$

[6] T. Takemoto, Y. Murata and T. Tanaka, ISIJ Int., Vol. 30 (1990) pp. 608-614

[7] T. Angel, J. Iron Steel Inst., Vol. 177 (1954), pp. 165-174

[8] G.A. Fontalvo, R. Humer, C. Mitterer, K. Sammt and I. Schemmel, Wear, Vol. 260 (2006) pp. 1028-1034 